\title{
The role of ophthalmology departments in overcoming health care disparities
}

\author{
Rebecca J. Salowe, Prithvi Sankar, Eydie Miller-Ellis, Maxwell Pistilli, Gui-shuang Ying, Joan M. O’Brien * \\ Scheie Eye Institute, University of Pennsylvania, Philadelphia, Pennsylvania, USA
}

Received: July 26, 2015

Accepted: September 15, $2015 \quad$ Online Published: September 22, 2015

DOI: $10.5430 /$ jer.v2n1p25

URL: http://dx.doi.org/10.5430/jer.v2n1p25

\begin{abstract}
Ophthalmology departments can play a unique role in providing care for at-risk patients. This study analyzed the age, gender, and socioeconomic measures for 267,286 unique African American patients seen at University of Pennsylvania Health System (UPHS). Patients seen by the Ophthalmology Department $(n=33,801)$ were older and more likely to be from impoverished zip codes than those seen by other UPHS specialists. These results hint at several inherent advantages of ophthalmology departments in recruiting older, disadvantaged patients to their clinics. We found that supplementing this advantage with strong patient relationships, involvement of community leaders, and customized outreach efforts was key to overcoming access-to-care issues and to reaching these patients. This provides ophthalmologists with a unique opportunity to capture and refer systemic conditions with ocular manifestations and to possibly reduce disparities such as post-hospitalization readmission and mortality observed disproportionately in impoverished populations.
\end{abstract}

Key Words: African American, Ophthalmology, Health care disparities, Minority, Socioeconomic status, Poverty, Access-tocare, Community outreach

\section{INTRODUCTION}

Ophthalmology departments may be in a unique position to serve at-risk, disadvantaged, and minority patients. To better understand this responsibility, we characterized the socioeconomic environment of African Americans seen by the University of Pennsylvania Health System (UPHS) and examined the implications of these findings.

Using UPHS Electronic Health Records, we analyzed age, gender, and zip codes for 267,286 unique African American patients seen at UPHS from July 2010-May 2013. Median population density, income, education level, and other socioeconomic measures were determined for each subject's zip code (see Table 1). This socioeconomic data was extracted from the 2010 United States Census Summary File Three ${ }^{[1]}$ and the 2008-2012 American Community Survey (ACS) 5Year Estimates. ${ }^{[2]}$ Of the 267,286 patients included for analysis, 33,801 (12.6\%) unique African Americans were seen by the Ophthalmology Department on at least one occasion. Interestingly, patients seen by the Ophthalmology Department were significantly older and from more impoverished regions (lower median household income, lower median household value, and lower rates of health insurance) than those seen by other UPHS departments. Ophthalmology patients were also from areas with a higher percentage of African American residents, higher proportion of male-only households, and lower rates of married-couple households than other UPHS patients.

*Correspondence: Joan M. O’Brien, MD; Email: joan.o'brien@uphs.upenn.edu; Address: Scheie Eye Institute, 51 N. 39th Street, Philadelphia, PA 19104, USA.

Published by Sciedu Press 
Table 1. Socioeconomic characteristics of patients in UPHS seen by Ophthalmology versus patients in UPHS not seen by Ophthalmology $(\mathrm{n}=267,286)$

\begin{tabular}{|c|c|c|c|c|}
\hline \multirow[b]{2}{*}{ Characteristics } & \multicolumn{4}{|c|}{ Seen by Ophthalmologist } \\
\hline & $\begin{array}{l}\text { No } \\
n=233,485\end{array}$ & $\begin{array}{l}\text { Yes } \\
n=33,801\end{array}$ & $P$-value & $\begin{array}{l}\text { Age adjusted } \\
p \text {-value }\end{array}$ \\
\hline Age (years) & $38.6(0.44)$ & $50.7(0.88)$ & $<.001$ & \\
\hline \multicolumn{5}{|l|}{ Demographic and socioeconomic factors based on zip code } \\
\hline Population per sq. mile & $13,951(1,200)$ & 14759 (1589) & .15 & .03 \\
\hline \% African-American & $57.7 \%(4.8 \%)$ & $65.3 \%(5.3 \%)$ & $<.001$ & $<.001$ \\
\hline Median household income (\$) & $34,380(1,831)$ & $32,915(2,143)$ & .07 & $<.01$ \\
\hline Median household value (\$) & $58,699(4,067)$ & $54,711(4,441)$ & .01 & $<.001$ \\
\hline \% Living below poverty level & $28.9 \%(1.6 \%)$ & $29.4 \%(2.1 \%)$ & .55 & .16 \\
\hline$\%$ At least high school graduate & $81.0 \%(1.0 \%)$ & $80.9 \%(1.4 \%)$ & .93 & .47 \\
\hline$\%$ At least some college & $43.6 \%(1.7 \%)$ & $43.9 \%(2.3 \%)$ & .74 & .69 \\
\hline \% Bachelor's degree or higher & $15.0 \%(1.1 \%)$ & $14.7 \%(1.3 \%)$ & .60 & .11 \\
\hline \% Unemployment & $18.3 \%(0.8 \%)$ & $18.3 \%(1.2 \%)$ & .96 & .66 \\
\hline$\%$ of households that are family households & $57.8 \%(1.2 \%)$ & $57.3 \%(1.4 \%)$ & .37 & .47 \\
\hline$\%$ of family households that are married-couple households & $36.6 \%(1.8 \%)$ & $35.3 \%(2.2 \%)$ & .12 & .01 \\
\hline$\%$ of family households that are male-only & $10.8 \%(0.4 \%)$ & $11.4 \%(0.4 \%)$ & $<.01$ & $<.001$ \\
\hline$\%$ of family households that are female-only & $52.6 \%(1.7 \%)$ & $53.3 \%(2.1 \%)$ & .41 & .09 \\
\hline$\%$ of nonfamily households where householder lives alone & $89.3 \%(0.5 \%)$ & $89.7 \%(0.6 \%)$ & .11 & .29 \\
\hline$\%$ of population that was never married & $54.0 \%(1.0 \%)$ & $53.9 \%(1.2 \%)$ & .81 & .36 \\
\hline$\%$ of population that is married (excluding separated) & $23.6 \%(1.2 \%)$ & $23.0 \%(1.5 \%)$ & .30 & .10 \\
\hline$\%$ of population that is separated, widowed, or divorced & $22.4 \%(0.8 \%)$ & $23.1 \%(1.0 \%)$ & .02 & .11 \\
\hline$\%$ of population born outside of the US & $7.5 \%(0.9 \%)$ & $7.5 \%(1.0 \%)$ & .94 & .61 \\
\hline$\%$ with health insurance & $85.1 \%(0.5 \%)$ & $84.5 \%(0.5 \%)$ & $<.01$ & $<.001$ \\
\hline
\end{tabular}

These results hint at several inherent advantages of ophthalmology departments in recruiting at-risk patients to their clinics. The later onset of many age-related ophthalmological conditions, such as age-related macular degeneration, glaucoma, presbyopia, and cataract, likely explains the older age of our ophthalmology patients. We also hypothesize that vision problems and blindness may significantly impair quality of life and prompt disadvantaged groups to visit an ophthalmologist more than other specialists. The American Foundation for the Blind demonstrated that the greatest fear of most patients is blindness, over conditions such as cancer, AIDS, or heart disease. ${ }^{[3]}$ Manifestations of other systemic conditions may be less obvious to patients and thus less likely to encourage a visit to a physician. This presents a unique opportunity for ophthalmology departments to recruit at-risk patients and to capture, diagnose, and refer for treatment systemic conditions with ocular manifestations, such as diabetes, atherosclerosis, hypertension, renal failure, or arthritis.
However, access-to-care issues remain deeply rooted in these populations. National statistics indicate that individuals at greatest risk for vision threatening disease (African Americans, males, and low-income individuals) are the least likely groups to use eye care services. ${ }^{[4,5]}$ Additionally, almost half of patients at high risk for vision loss did not visit an eye doctor in the past year. ${ }^{[4]}$ This presents both a challenge and opportunity to ophthalmology departments: they have a slight advantage when recruiting at-risk patients, but these patients can be very difficult to reach. We believe that the most effective way to overcome this barrier and recruit at-risk patients is through strong patient connections, involvement of community leaders, and customized outreach efforts. Below we detail how each of these strategies has been applied in our Ophthalmology Department, followed by an example that utilizes all three approaches. 


\section{APPROACHES}

(1) Connection with patients: Our Ophthalmology Department is located in a primarily African American neighborhood and is composed of $31 \%$ non-Caucasian ophthalmologists. The specialists and staff form strong relationships with patients, which we believe is a large reason why many patients are willing continue visiting our Department. ${ }^{[6,7]}$ Studies have shown that physician recommendation is a very strong predictor of patients receiving an eye examination, so our physicians take special care to emphasize the importance of utilizing eye care services. ${ }^{[5]}$

(2) Involvement of community leaders: We also reach out to specific patient populations through involvement of local community leaders, including pastors of African American heritage churches, leading writers in African American newspapers, hosts of African American health radio programs, and our local African American Councilwoman. Programs that facilitate community engagement and cultural competency have been proven to reach the most patients. ${ }^{[6,8]}$

(3) Customized outreach efforts: To reach the most at-risk and undertreated areas of Philadelphia, we drive a fullyoutfitted eye lane within a mobile van to these areas, offering free eye screenings to all who are interested. We have coupled these efforts with blood pressure screenings and will soon add diabetic screening and prescriptions for discounted eyeglasses to our outreach. The Department also actively provides eye care to underserved populations through programs such as 4Sight, The Pew Trust for Vulnerable Adults Program, and Penn Sight Savers. Scheie faculty, residents, and Penn medical students also voluntarily staff the Puentes de Salud clinic, which we provided with a fully-outfitted eye lane.

We examine the Primary Open-Angle African American Glaucoma Genetics (POAAGG) study for a concrete example of how these strategies can be applied. ${ }^{[9]}$ The challenge of the POAAGG study is to recruit more than 8,000 African American patients from the Philadelphia region. So far, the study has recruited more than 4,000 African American patients since enrollment began in July 2010 and NIH funding was received in March 2014. The majority of POAAGG participants were from regions characterized by lower access to primary care ${ }^{[10,11]}$ and increased risk of adverse all-cause readmission and death after hospital discharge. ${ }^{[12-14]}$ To overcome these barriers and achieve high enrollment numbers, we implemented the outreach strategies described above. We reached out to the West Philadelphia community through a series of advertisements about POAAGG in the local subway (SEPTA), African American talk radio, pastors of African American churches, African American government officials, and African American newspaper articles (Philadelphia Tribune). These efforts have been very successful, with a resultant large volume of calls to our Clinical Research Coordinators to schedule appointments for enrollment in the study. In addition, we drove a fully-equipped ophthalmology van to underserved areas of Philadelphia to offer free glaucoma screenings. We also hosted outreach events at community centers, federally qualified health centers, retirement communities, and churches to evaluate these populations for glaucoma and to enroll subjects who would otherwise not be seen by ophthalmologists. We believe that these efforts are a large reason why patients visited their glaucoma specialists at the Ophthalmology Department and enrolled in POAAGG. We are NIH funded to perform genotyping on these patients, and once this genotypic data is obtained, it can be inexpensively re-analyzed to elucidate the genetics of other diseases that disproportionately affect African Americans. We hope this will provide resources for other scientists with different research interests to investigate this understudied and underserved population.

\section{Conclusions}

Ophthalmology departments are at a unique advantage when recruiting older, disadvantaged patients to their clinics. Supplementing this advantage with strong patient relationships, involvement of community leaders, and customized outreach efforts is key to reaching these patients, as seen with our POAAGG subjects $(\mathrm{n} \sim 4,000)$ and ophthalmology patients as a whole $(n=33,801)$. This presents a unique opportunity for ophthalmology departments to reach the most at-risk patients living in any urban setting, while also capturing and referring systemic conditions with ocular manifestations. Ophthalmology departments may even play a role in helping patients obtain insurance and reducing major disparities such as post-hospitalization readmission and mortality observed disproportionately in at-risk populations. ${ }^{[12,15]}$

\section{FINANCIAL SUPPORT}

This work was supported by the National Eye Institute, Bethesda, Maryland (grant: \#1RO1EY023557-01) and the Department of Ophthalmology at the Perelman School of Medicine, University of Pennsylvania, Philadelphia, PA. Funds also come from the F.M. Kirby Foundation; Research to Prevent Blindness Unrestricted Grant; The Paul and Evanina Bell Mackall Foundation Trust; and the National Eye Institute, National Institutes of Health, Department of Health and Human Services, under eyeGENETM and contract Nos. HHSN260220700001C and HHSN263201200001C. The sponsor or funding organization had no role in the design or conduct of this research. 


\section{REFERENCES}

[1] Mesenbourg T, Potok N, Vitrano F, et al. 2010 Census Summary File 3. In: Commerce, ed. Washington DC; 2011.

[2] The 2008-2012 American Community Survey 5-Year Estimates In: Commerce, ed.; 2013.

[3] Key Findings: National Poll on Severe Vision Loss/Blindness American Foundation for the Blind 2014.

[4] Zhang X, Saaddine J, Lee P, et al. Eye care in the United States: do we deliver to high-risk people who can benefit most from it? Archives of ophthalmology. 2007; 125: 411-8.

[5] Baker R, Bazargan M, Bazargan-Hejazi S, et al. Access to vision care in an urban low-income multiethnic population. Ophthalmic epidemiology. 2005; 12: 1-12.

[6] Haynes-Maslow L, Godley P, Dimartino L, et al. African American women's perceptions of cancer clinical trials. Cancer Med. 2014; 3: 1430-9. PMid:24905181. http://dx.doi.org/10.1002/cam 4.284

[7] Komaromy M, Grumbach K, Drake M, et al. The Role of Black and Hispanic Physicians in Providing Health Care for Underserved Populations. The New England journal of medicine. 1996; 334: 1305-10. PMid:8609949. http://dx.doi.org/10.1056/NEJM199605163 342006

[8] Ghebre R, Jones L, Wenzel J, et al. State-of-the-Science of Patient Navigation as a Strategy for Enhancing Minority Clinical Trial Accrual. Cancer. 2014; 120: 1122-30. PMid:24643650. http: //dx.doi.org/10.1002/cncr. 28570

[9] Charlson E, Sankar P, Miller-Ellis E, et al. The Primary Open-Angle African-American Glaucoma Genetics (POAAGG) Study: Baseline
Demographics. Ophthalmology. 2015; 122: 711-20. PMid:25576993. http://dx.doi.org/10.1016/j.ophtha.2014.11.015

[10] Misky GJ, Wald HL, Coleman EA. Post-hospitalization transitions: Examining the effects of timing of primary care provider followup. Journal of hospital medicine: an official publication of the Society of Hospital Medicine. 2010; 5: 392-7. PMid:20578046. http://dx.doi.org/10.1002/jhm.666

[11] Asplin BR, Rhodes KV, Levy H, et al. Insurance status and access to urgent ambulatory care follow-up appointments. JAMA: the journal of the American Medical Association. 2005; 294: 124854. PMid:16160133. http://dx.doi.org/10.1001/jama. 294. 10.1248

[12] Kangovi S, Mitra N, Grande D, et al. Patient-centered community health worker intervention to improve posthospital outcomes: a randomized clinical trial. JAMA internal medicine. 2014; 174: 53543. PMid:24515422. http://dx.doi.org/10.1001/jamainter nmed. 2013.14327

[13] Elixhauser A, Au DH, Podulka J, et al. Readmissions for Chronic Obstructive Pulmonary \#121. 2006; 2008 SRC - GoogleScholar.

[14] Rodriguez-Artalejo F, Guallar-Castillon P, Herrera M, et al. Social network as a predictor of hospital readmission and mortality among older patients with heart failure. J Card Fail. 2006; 12: 6217. PMid:17045181. http://dx.doi.org/10.1016/j.cardfail. 2006.06 .471

[15] Kangovi S, Grande D, Trinh-Shevrin C. From Rhetoric to Reality Community Health Workers in Post-Reform U.S. Health Care. New England Journal of Medicine. 2015; 372: 2277-9. PMid:26061832. http://dx.doi.org/10.1056/NEJMp1502569 